\title{
Nutrigenomics: future for sustenance
}

\author{
Prem Lal' ${ }^{1}$, Remya Ramachandran', P. T. James ${ }^{2}$, Rajeevan K. ${ }^{3}$, Aju Ravindran ${ }^{4}$, \\ Durga Balakrishnan ${ }^{3}$, Ajith Bhasker, ${ }^{5}$ Sasidharan ${ }^{6}$, Babu Francis ${ }^{6}$, Gopalan A. V. ${ }^{6}$, \\ Subbaraman K. R. ${ }^{6}$, Kanniyan Binub ${ }^{1 *}$
}

\begin{abstract}
${ }^{1}$ Department of Community Medicine, Malabar Medical College and Research Center, Kerala, India
${ }^{2}$ Department of Pulmonary Medicine, Malabar Medical College and Research Center, Kerala, India

${ }^{3}$ Department of Pathology, Malabar Medical College and Research Center, Kerala, India

${ }^{4}$ Department of ENT, Malabar Medical College and Research Center, Kerala, India

${ }^{5}$ Department of Emergency Medicine, Malabar Medical College and Research Center, Kerala, India

${ }^{6}$ Department of Pediatrics, Malabar Medical College and Research Center, Kerala, India
\end{abstract}

Received: 30 December 2021

Accepted: 14 January 2022

\section{*Correspondence:}

Dr. Kanniyan Binub,

E-mail: kanniyanbinub@gmail.com

Copyright: () the author(s), publisher and licensee Medip Academy. This is an open-access article distributed under the terms of the Creative Commons Attribution Non-Commercial License, which permits unrestricted non-commercial use, distribution, and reproduction in any medium, provided the original work is properly cited.

\begin{abstract}
Nutrigenomics deals with the effect of foods and food constituents on gene expression. It is a new concept in disease prevention and cure. Nutrigenomics conveys how nutrients influence our body to express genes, whereas nutrigenetics refers to how our body responds to nutrients. The various bioactive food components can alter the gene expression mechanisms. But our actual knowledge is so insufficient that the only use of such information may help to satisfy our imagination. If science could arrive at some more precise facts, that would have vast applications in medicine.
\end{abstract}

Keywords: Nutrigenomics, Health, Life

\section{INTRODUCTION}

Nutrigenomics is a very potential science which was seeded way back in 18th centuries. These food habits and lifestyle changes predispose to diet-related diseases and detrimental health effects. ${ }^{1}$ Lavoisier is a French nobleman who had conveyed long ago that nutrition has often been the subject of conjectures and ingenious hypotheses.

Way back in historical times, there were attempts from renowned scholars to explain relationship between diet and health. India is renowned for rich culture and heritage. The Tamil language is considered to be the oldest language in human history.

Tamil literature is so vast, and the richness of the language is expressed in terms of poems. For centuries, poems guided the way of life for the people in Tamil Nadu irrespective of their times. The values the Tamil literature has imparted into every person are evident in how they conduct their lives.

Their life is so simple as the language is. The moral and ethical values that Tamil Nadu people hold are sky-high and are rooted in their literature. One of such literature is Thirukkural. Thirukkural is not religious or political literature. Thirukural expresses the intimacy of life and the intensity of impact it has regard to life on earth. The SOAS university of London has opened a statue for thiruvallur, who had written Thirrukural in the year $2018 .^{2}$

There are some insights from this ancient literature, Kural No.945 says- it states, if only agreeing foods are consumed, that too, with limitations, there are no health problems to living beings. The inner meaning is that nonagreeing foods should be avoided and agreeing foods 
should be consumed within a limit. There is a rise in autoimmune diseases, for which we have identified a few of the trigger factors that aggravate the disease pattern. The trigger factors in the food may involve allergic contents specifically affecting a few persons only. Nevertheless, the designs of food allergens are identified and the disease condition improves dramatically without any medications by avoiding those allergens. Examples of food allergens include cow's milk (lactose), gluten (wheat) and seafood. Two thousand years ago, Thiruvalluvar had advised identifying agreeing food stuff and consuming without exceeding the limit.

Similarly, Unani is a stream of medicine which has separate speciality on dietotherapy. The Unani system of medicine is based on the concept of Asbab-e-SittaZaruriya (six essential prerequisites) which includes Hawa-e-Muheet (atmospheric air), MakoolatwaMashroobat (foods and drinks), Harkat waSukoon-- Badni (physical activity and repose), Harkat wa-SukoonwaNafsani (mental activity and repose), Naumwa-Yaqza (sleep and wakefulness) and Ehtibaswa-Istifragh (retention and elimination). These six factors are essential for living human beings. Nobody could escape these prerequisites of life. The management of the diseases in Unani system of medicine is largely based on the holistic approach with an aim to treat body, mind and soul. Four core modes of treatment are usually practiced such as Ilaj bit tadbeer (regimenal therapy), Ilajbilghiza (dietotherapy), Ilaj bid dawa (pharmacotherapy) and Ilajbil yad (surgery). The Ilajbilghiza is a speciality in Unani which focus on modulation in dietary habits, i.e. fasting, use of food stuff in more quantity having less nutritional value or less quantity having more nutrients or vice versa. ${ }^{3}$ Insights from history and literature would help the presentday scientist to research further on diet and health.

Nutrigenomics is a new concept, but the achievability of its benefits is challenged by the methodological limitation that is encountered during clinical research in the field. Nutrigenomics is still progressing, but it could one day revolutionize the way we eat and how physicians direct our medical care using food as medicine. We need to help people control their health, understand their health risks and decrease chronic diseases. Therefore, many research activities are undergoing in this field for the better health in the coming future.

Thierry Hurlimann did a systematic analysis on clinical studies in nutrigenetics published between 1998 and 2007; 173 publications were identified. ${ }^{4}$ There is no consistency in the way participants' origin (ancestry, ethnicity, or race) and ages are described in publications. The majority of identified studies were conducted in Europe and North America, which were focused on 'white participants'.

It also shows that the pregnant women (and fetuses), minors, and the elderly remain underrepresented. They concluded that if nutrigenetics is to benefit whole populations and be used in public and global health care systems, equitable representation and precise illustration of participants are needed.

Both nutrigenomics and nutrigenetics research fields have raised expectations about their potential benefits. The result of the analysis was to take caution and avoid the premature dissemination of potential benefits of nutrigenetics among various audiences.

In another study done at the University of Toronto, Canada, in 2014 under the topic "Disclosure of Genetic Information for Personalized nutrition and change in Dietary intake". 5 The background of the study was using consumer genetic tests and personal genetic information has become increasingly accessible. These information helps in preventing chronic diseases; at the same time, the effects of disclosing genetic information on dietary behaviour have not been well explored. The study's objective was to determine the impact of DNA-based dietary advice on caffeine, vitamin $\mathrm{C}$, added sugar and sodium intake and analysed the individual perception of genetic testing and personalized nutrition. The methodology included a randomized control trial conducted with men and women aged 20-35 years. The intervention group and control group are decided. DNA based dietary advice was given to subjects in the intervention group, and general dietary recommendations to the control group. Food frequency questionnaires were collected at baseline, 3 and 12 months and general linear models were used to compare changes in intake between groups. At 12-months, participants in the intervention group who possessed a risk version of the ACE gene, and were advised to limit their sodium intake, significantly reduced their sodium intake (mg/day) compared to the control group.

Throughout the 20th century, nutritional science focused on finding vitamins and minerals, defining their use and preventing deficiency diseases. But recently, the nutritionrelated health problems of the developed world shifted to overnutrition, obesity and type 2 diabetes. And the focus of modern medicine and nutritional science changed to health, development and growth. As there is an epidemic rise in diseases pertaining to nutrition, there is a need to understand the biology of the masses at a molecular level.

\section{FACTORS RESPONSIBLE FOR THE SHIFT}

The completion of several large human genome projects has markedly altered the research agenda by drawing attention to the importance of genes in human nutrition and has provided a wealth of new genetic information to be explored. There has been a growing recognition that micronutrients and macronutrients can be potent dietary signals that influence the metabolic programming of cells and have an essential role in the control of homeostasis. Nutrition researchers have increasingly recognized that genetic predisposition can be an essential contributor to the leading cause of mortality linked to diet, such as cardiovascular diseases, type 2 diabetes and cancers. The 
innovations in genetic studies can perform a detailed molecular analysis. The analysis helps to focus on how nutrition impacts genetic makeup. So, the time is now ripe for new nutritional strategies to make a change in the present way of thinking about food and to change the way evaluating nutritional status and responses.

\section{DIETARY SIGNATURE}

It is a pattern of gene expression, protein expression and metabolite production in response to certain nutrients. This nutrigenomics seeks to know these dietary signatures in specific cells, tissues and analyses how nutrition influences homeostasis. It also reveals why and how people respond differently to the same nutrient.

\section{PRINCIPLES OF NUTRIGENOMICS}

Improper diet is a risk factor for various diseases. The dietary component can alter the gene expression. Based on an individual's genetic makeup, diet influences the balance between health states and disease states. Specific genes which are controlled by some diets may alter the onset, incidence, progression or severity of chronic disease. ${ }^{5}$

\section{OTHER ESSENTIAL CONCEPTS ABOUT GENE EXPRESSION}

Some dietary habits alter the balance between health and disease by acting directly or indirectly on the gene. For example, if there is polymorphism in nutrient regulated genes, the risk of developing diseases is high. So in the genetically predisposed individual, the concept of a personalized diet can reduce the risk of developing these diseases.

\section{HOW DOES DIET INTERACT WITH GENE}

Diet can act as a transcription factor that binds DNA directly, causing gene expression. It can alter the structure of DNA so that gene expression is also altered .Single nucleotide polymorphism can also change the gene expression

\section{HOW DOES THE DIET ALTER THE GENE EXPRESSION}

Gene passes the signals to the ribosome to produce a particular enzyme that will destroy toxins. Some foods such as cauliflower, broccoli, and brussels sprout contain a specific chemical that will directly act on gene expression result in the synthesis of these enzymes.

\section{DISEASE AND GENE-DIET INTERACTION}

Some monogenic diseases can be prevented by dietary habits modification.There is a genetic defect in an autosomal recessive condition like Phenylketonuria. Because of this defect, there is impairment in the metabolism of phenylalanine. The impairment, in turn, leads to the accumulation of phenylalanine in the body. Similarly, individuals deficient in aldehyde dehydrogenase enzyme should avoid consuming a high protein diet, including egg, fish and chicken.

\section{NUTRIGENOMIC CONCEPTS IN TYPE 2 DIABETES MELLITUS}

By identifying diet regulated genes and their expression mechanism, diseases can be controlled and could prevent chronic diseases such as type 2 diabetes mellitus and improve the health status of individuals.

\section{NUTRIGENOMICS AND CANCER}

If there is a gene-diet interaction, the risk of developing cancer can be markedly increased. So inherited mutations in genes can increase susceptibility to cancer.

\section{NUTRIGENOMICS \\ AND \\ DIET \\ SUPPLEMENTATION}

Development of food technology brought about a change in the quantity and quality of the various fatty acids. Ayurvedic medicine prescribes plant-based medication. Turmeric has been shown to be a potent antioxidant and anti-inflammatory agent as a chemopreventive agent. The review by Singh and Jaiswa (2011) has revealed the application of Nutrigenomics in male fertility. Folate, vitamin B12, and zinc supplementation positively affect spermatozoa number and mortality. ${ }^{6}$

\section{NUTRIGENOMICS IN CARDIOVASCULAR MEDICINE}

In a study, Dolores Corella and Jose M. Ordovas studied cardiovascular genetics. Nutrigenomics helps in better preventing and treatment of cardiovascular diseases. It has an important role in the current health status of our world populations. It can be achieved by optimizing individuals' dietary intakes, but nutrigenomics is still in its progressive stage and developing its research methodology, continuously learning from its achievements. Scientific evidence is needed for its effective utilization in clinical practice. Cardiovascular diseases are a group of diseases in which most progress has been made on the knowledge of their risk factors. Identifying diet-gene interaction can help in CVD prevention and treatment. ${ }^{7}$

\section{GENOMICS OF VITAMIN D}

Nutrigenomics deals with how environmental factors such as food intake and lifestyle influence the genome's expression. Vitamin D3 represents such an important influencing factor. It's metabolite 1a, 25 dihydroxy vitamin D3, which binds with high affinity to the vitamin D receptor; the secosteroids directly affect the epigenome and transcriptome at thousands of loci within the human genome. Vitamin D3 controls calcium homeostasis and modulate the responses of the innate and adaptive immune 
system. On adequate UV-B exposure, a human can synthesize vitamin D3 endogenously in their skin. But nowadays, lifestyle changes make people take supplement pills or diet for vitamin D3. Individualized molecular response to vitamin D3 is required to obtain better clinical benefits in preventing osteoporosis, sarcopenia, autoimmune diseases and possibly different types of cancers. $^{8}$

\section{HOW DOES NUTRIGENOMICS IMPACT HUMAN HEALTH}

In a study by Giuditta Perozzi on the impact of nutrigenomics, it is assumed that the relationship between nutrition and medicine has roots back in IV century BC when Hippocrates suggested that balanced nutrition could be a valid alternative to medication in maintaining good health. Such ancient knowledge is trying to practice following research regarding nutrients and bioactive food components in controlling gene expression. ${ }^{9}$

\section{NUTRIGENOMICS RESEARCH CENTRES}

Nutrigenomic research requires a considerable investment to have nutrigenomics programmes. At international level there are National centre on minority health and health disparities (NCMHD), Centre of excellence for nutritional genomics (at the University of California at Davis in the United States) and German Berlin- Brandenburg nutrigenome work. Two Dutch nutrigenomics centres are present were centre for human nutrigenomic innovate cluster genomic project. But India doesn't figure anywhere in this and is yet to make a start.

But at national level, there are some private agencies which have initiated a few work. Although not precise, a little closely related to Nutrigenomics, but they are gene support nutrigenomics. It is based in Pune, and is a joint venture. They provide wide-ranging test panels to healthconscious individuals, which are capable also to predict the results or the risk associated with specific lifestyles.

\section{ADVANTAGES OF NUTRIGENOMICS}

It helps in dealing with healthy diet and lifestyles, brings awareness regarding to the risk of certain conditions. Improving the quality of life and focusing on the prevention of disease.It has decreased morbidity and premature mortality and there are limited health care cost. The disease susceptibility and the mechanism involved can be understood efficiently.

\section{DISADVANTAGES OF NUTRIGENOMICS}

A new field of research still has a lot to explore. Genes are one of the factors which influence the health and dietary choices, so that they won't solve every diet problem. It has to include lifestyle, health history, health status, personal preference, cultural identity, the willingness of the patient to change and their own health goals in our work.
Difficulty in the availability of consumer genetic testing for diet purposes are there. A skilled clinician does not interpret it. Instead, they use a polygenic approach that how all of the genes are part of more significant systems in the body. ${ }^{10}$

\section{DISCUSSION}

The search for 'healthy food' in Google searches and Youtube channels on healthy recipes is trending these days. More than 100 channels are hosting only about healthy food. All these channels have millions of views and huge subscribers. So, where are these healthy people? Are these healthy people aliens? Do all the subscribers have it all? Never before in the history of humanity, so much research and knowledge about human well-being are available at the fingertips. But as health care professionals, not witnessing a massive change in people's health, instead the trend of disease is on a high note.

Nutrigenomics is the new frontier of nutrition science. Nutrigenomics interplay nutrition, human genetics and its effect on health. In the current era of information technology, there is increased awareness regarding essential nutrition among lay people who have access to the internet. Even so, preventable non-communicable diseases like type 2 diabetes and hypertension remains an uncontrolled pandemic.

Everybody knows something about food, simultaneously the knowledge may not have a scientific basis. Many academic communities are coming out with a new therapeutic diet daily. We can witness these on social media platforms as the cure food or recipes to reduce body weight, pain killer recipes and so on. But unfortunately, none of the dietary techniques has effectively reduced the burden of lifestyle diseases, including diabetes, hypertension, cancer, and other nutrition-related disorders.

Though nutrition plays a vital role in most diseases, the eating pattern has not changed for the entire community. Even though most educated people have good awareness about nutrition, there is seldom time to follow all in a day owing to the busy lifestyle. As a result, only a handful of people follow a strict diet pattern daily. Moreover, there is no food chain system in the environment to support a healthy person to follow a healthy diet routine on the go.

The genomes, proteome and metabolome in the human chromosome are considered to influence health. ${ }^{11}$ The change in health is not uniform worldwide partly because human responses are highly variable. There are vigorous attempts going on globally to find out the association of whole-genome with chronic disease states. ${ }^{12}$

\section{CONCLUSION}

Nutrigenomics ensure maximum quality of life for a maximum period through personalized health care, focusing more on preventive care rather than curative 
treatment. This concept has recently received much attention because of its potential effect on preventing and treating chronic diseases and certain cancers through small but highly informative dietary changes. So, nutrigenomics and personalized nutrition is a need of the hour.

Funding: No funding sources

Conflict of interest: None declared

Ethical approval: Not required

\section{REFERENCES}

1. Sales NM, Pelegrini PB, Goersch MC. Nutrigenomics: definitions and advances of this new science. J Nutr Metab. 2014;2014:202759.

2. Twitter. SOAS University of London, 2021. Available at: https://twitter.com/soas/status/97652. Accessed on 18 December 2021.

3. Bashir F, Akhthar J. Ilajbil-Ghiza (Dietotherapy) in Unani system of medicine- An appraisal. EPJMR. 2018.

4. Hurlimann T, Stenne R, Menuz V, Godard B. Inclusion and exclusion in nutrigenetics clinical research: ethical and scientific challenges. J Nutrigenet Nutrigenomics. 2011;4(6):322-43.

5. Abete I, Agirre X, Ahlgren J, Aranburu G, Aller R, Lacueva C, et al. In: Caterina RD, Martinez JA, Kohlmeier M, eds. Principles of Nutrigenetics and Nutrigenomics. India: Academic Press; 2020.

6. ProQuest. Disclosure of Genetic Information for Personalized Nutrition and Change in Dietary Intake,
2021.

Available at: https://www.proquest.com/openview/a29686c86998 c39902d83679701e42ce/1 ?pqorigsite $=$ gscholar\&cbl $=18750$. Accessed on 18 December 2021 .

7. Nutrigenomics in Cardiovascular Medicine. Circulation: Cardiovascular Genetics, 2017. Available at: https://www.ahajournals.org/doi/full/10.1161/CIRC GENETICS.109.891366. Accessed on 18 December 2021.

8. Nutrients. Nutrigenomics of Vitamin D, 2021. Available at: https://www.mdpi.com/20726643/11/3/676. Accessed on 18 December 2021.

9. Virgili F, Perozzi G. How does Nutrigenomics impact human health? IUBMB Life. 2008;60(5):3414.

10. Reddy VS, Palika R, Ismail A, Pullakhandam R, Reddy GB. Nutrigenomics: Opportunities \& challenges for public health nutrition. Indian J Med Res. 2018;148(5):632-41.

11. Ordovas JM, Mooser V. Nutrigenomics and nutrigenetics. Curr Opin Lipidol. 2004;15(2):101-8.

12. Ferguson LR. Nutrigenomics approaches to functional foods. J Am Diet Assoc. 2009;109(3):4528.

Cite this article as: Lal $P$, Ramachandran $R$, James PT, Rajeevan K, Ravindran A, Balakrishnan D, et al. Nutrigenomics: future for sustenance. Int J Res Med Sci 2022;10:541-5. 